\title{
A Poética do corpo e sua inteligência pelo percepto e pelo afeto
}

\author{
The poetic of the body and its intelligence by perception and affection
}

\author{
Maria Lúcia Galvão Souza \\ Universidade do Estado do Rio de Janeiro
}

\section{RSUMO:}

Este trabalho tem por finalidade relatar e analisar a atividade desenvolvida na forma de oficina durante o evento de extensão universitária "Políticas/poéticas de contágio: ensaio de viver entre muitxs", organizado pelo Instituto de Psicologia da UERJ. A Oficina Poética do Corpo teve o intuito de abrir caminhos para o desenvolvimento da consciência de si e do outro, potencializando o ato de criação na forma de vivências práticas, funcionando como uma poética do encontro. Dessa forma, serão relatados os passos para a execução do projeto que culminou em uma rica experiência transdisciplinar na forma de oficina livre, com caráter essencialmente prático, utilizando conceitos relacionados a experiência, corpo, jogo e afeto que foram explanados na forma de ações sensíveis e lúdicas a partir da investigação de narrativas corpóreas, desvelando afetos com alunos de diferentes áreas de conhecimento e de diferentes instituições de ensino.

Palavras-chave: corpo; afetos; experiência lúdica.

\begin{abstract}
:
This article has the finality of reporting and analyzing the activy developted in a workshop which was made during the university extension scholarship event, Políticas/poéticas de contágio: ensaio de viver entre muitxs, organized by the Institute of Psicology from UERJ. The workshop had the objective of opening ways to develop the self-sense and of the other, increasing the act of creation in shape of pratical experiences, working like a poetics of the encounter. In this way, in this paper will be reported the steps for the execution of the Project that culminated in a rich and transdisciplinary experience in this free workshop, which had a essentially practical character, using concepts related to the experience, the body, the game and the affection that was explained in in the form of sensitive and playful actions.
\end{abstract}

Key-words: body; affection; playful experience.

DOI: 10.12957/mnemosine.2020.57652

\section{A poética do afeto}

Como professora de Dança do Instituto de Artes da UERJ, artista, coreógrafa, diretora de movimento, acostumada a realizar ações artístico-pedagógicas variadas, mas normalmente 
voltadas para pessoas que, de uma forma ou de outra, são ligadas ao universo das artes da cena, resolvi desde 2017 começar a desafiar esses limites. Dessa forma, o projeto foi também direcionado a pessoas de variados campos de conhecimento, níveis escolares, sociais e gêneros, com formatos de trabalho mais curtos, demonstrando que, apesar do desconhecimento da linguagem corporal, os resultados que podem ser apresentados em nível de autoconhecimento e conscientização são muito significativos e transformadores.

A proposta da oficina é realizar experiências corporais que enfoquem a investigação e a descoberta de múltiplas possibilidades expressivas relacionadas à linguagem e à comunicação do corpo com o mundo que o cerca. Essas pesquisas laboratoriais fazem parte de algumas atividades realizadas por docentes e discentes da UERJ e da UFRJ que integram o projeto de Extensão da UERJ Kinesis: Núcleo de Artes Cênicas e o Grupo de Pesquisa Investigações sobre o Corpo Cênico (CNPq/UFRJ).

A partir desses processos de pesquisa teórico-práticas desenvolvidos no grupo, identificamos a importância da experiência como um fator primordial para a formação dos artistas e para as pessoas de uma forma em geral. Pela aplicação de jogos que colocam os atuantes em processos de improvisação, percebemos objetivamente o desenvolvimento de corpos mais sensíveis e propositivos em suas manifestações. Por meio de memórias e afetos dos participantes, exploramos relações corporais por meio de diferentes formas de expressão, transgredindo, assim como propõe Artaud (1993), os significados estratificados dos sons, gestos, palavras e objetos.

Desta forma, propomos nessa oficina desenvolver estratégias para a descoberta de possibilidades do corpo que potencializem a expressão humana, utilizando exercícios e jogos cênicos como ferramentas para sensibilizar o corpo e alargar seu espectro de experiências físicas, revelando um estado de potência e atenção latentes que servem de dispositivo para acionar sensibilidades e revelar acontecimentos poéticos. Recursos como os ritmos respiratórios, o tamanho do movimento, a força e a velocidade da ação, as bases de apoio no solo, o desenho da trajetória do movimento, entre outros, ganham força expressiva quando são produzidos junto com canções, palavras e sons que criam sentidos para esse universo simbólico das linguagens. Assim, temos como objetivos propostos para essa oficina sensibilizar o corpo para estar presente e focado no espaço e no tempo, alcançando a integração em suas ações e assim comunicar-se com o outro de forma plena; transformar o espaço, preenchendo-o de poesia 
pelo entrelaçamento das experiências da ação através da palavra, da canção e do próprio movimento e desvelar seu próprio corpo na experiência com o grupo.

O Corpo, nossa forma de ser e estar no mundo, nos possibilita utilizá-lo como meio de autoconhecimento por vias que conduzem às suas próprias possibilidades e funções, levando a um desenvolvimento de se descobrir e de se desenvolver. Por isso, mergulhar em um formato de encontro, como propõe o evento Políticas/poéticas de contágios: ensaios de viver entre muitxs, enaltecendo apostar nesse "contágio" pela via da experimentação e da sensibilização de si e do coletivo como método de fazer circular as experiências, foi uma experiência potente que venho aqui detalhar e analisar.

\section{Metodologia poética}

A proposta tem como objetivo promover um encontro de subjetividades, a partir de um investimento afetivo do corpo, proporcionando a criação de espaço relevante para uma experiência prática e sensível, estimuladora dessa inteligência corporal. Como afirma o filósofo André Simha, a inteligência do corpo é, ao mesmo tempo, “a compreensão intuitiva de seu próprio corpo, e a integração pelo próprio corpo de esquemas de ação e de movimentos que contribuem para o êxito da ação" (SIMHA, 2009: 204).

Para a realização da Oficina Poética do Corpo, visando o desenvolvimento dessa inteligência corporal, foi solicitado à organização do evento que providenciasse um espaço físico apropriado, amplo, sem cadeiras e o chão sem irregularidades e bem limpo. Dessa forma, possibilitou-se aos partícipes a sua utilização como base de apoio para o corpo, quando deitados ou sentados, e a realização de movimentos livres no espaço, sem a preocupação de se machucarem.

Primeiramente, sem mencionar meu nome, solicitei aos participantes que ao entrar na sala já tirassem seus sapatos. Isso prontamente provocou certo estranhamento, por não ser comum esse tipo de contato dos pés com o chão em encontro acadêmico. Eu me apresentei e falei dos objetivos do trabalho a serem vivenciados ao longo da manhã.

Iniciamos os trabalhos com os participantes sem sapatos e deitados no chão no lugar que eles escolheram dentro da sala. Meio desconfiados pela mudança de padrão de comportamento, lhes foi pedido que buscassem perceber o desenho do corpo naquele espaço e que percebessem o contato das partes do corpo no solo, estimulando essa compreensão intuitiva do seu próprio corpo. Em seguida, foi proposta a ação do movimento natural de espreguiçar, 
trabalhando a ideia de corpo expandido e retraído, corpo fechado e aberto, tudo associado à respiração, objetivando um relaxamento natural do corpo e a integração do próprio corpo de esquemas de ação e de movimentos que contribuem para o êxito da ação.

Depois disso, buscando a consciência do corpo no espaço, lhes foi pedido que ficassem em decúbito dorsal, tranquilos e relaxados e acompanhados por uma música bem calma e instrumental, concentrando a atenção para o ato de respirar. Através desse eixo, corpo/espaço/respiração, direcionamos seu pensamento e sensação para a sua respiração e realizamos algumas variações em cima dela, buscando a ação consciente, como propõe Meyer:

A ação "consciente" emerge (incluindo a do ator), muitas vezes, de movimentos aparentemente involuntários, orquestrados em uma rede neuronal rica em referências, memórias passadas e percepção do momento presente sem o controle intencional do agente. Há um terreno desconhecido (criativo) que não depende plenamente da intenção do agente, mas que pode ser acionado pela parte cabivel ao exercício da sua vontade. A busca do detalhamento preciso das ações e a conexão com o momento presente contribui para que se desencadeiem espaços de imprevisibilidade e organicidade (MEYER, 2010:113).

Mudando o foco dos participantes sobre a respiração, sem realizar mudança do plano do corpo e com os olhos bem abertos, os participantes passaram a realizar o reconhecimento visual do espaço da sala. Primeiramente, só com o movimento dos olhos e, em seguida, com o olhar e a cabeça, recolhendo o máximo de informações do local, reconhecendo o espaço e se reconhecendo como parte dele, explorando a percepção do corpo, do espaço e do todo, pois a percepção é o nosso primeiro contato com as coisas e com o mundo.

Segundo José Gil (2004), a fenomenologia teve o mérito de considerar o corpo no mundo. Para ele, não se trata de uma perspectiva terapêutica, mas do estudo do papel do que chama do "Corpo próprio" na constituição do sentido. Para Gil, a noção de corpo próprio compreende ao mesmo tempo o corpo percebido e o corpo vivido. A partir dessa perspectiva, a próxima etapa do trabalho buscou estimular os sentidos, retirando a possibilidade da visão e estabelecendo contatos manuais com diferentes objetos. Cada participante pôde explorar através de seu "corpo próprio", utilizando quase todos os sentidos, os objetos, retirando deles diferentes tipos de informações, sem dar nomes, apenas características. Os alunos manusearam objetos de diversos tamanhos, formas, texturas, pesos, temperaturas, cheiros e até sabores, e foram, a cada troca de objeto, afetados pela possibilidade das descobertas. A sensação significa o processo de experimentar o mundo através dos sentidos, o que é provido pelos órgãos sensoriais. Os órgãos sensoriais, por sua vez, captam estímulos de qualquer classe. Ou seja, 
sensação é o ato de receber estímulos do ambiente... Pois, como afirma Pavis, "Um afeto é um eco em nós daquilo que o corpo faz ou sofre”. (PAVIS, 2017:23).

Até esse momento trabalhamos ativando memórias, que implicam múltiplos níveis sensoriais, mentais e reflexos, proporcionando, através dos sentidos, a ação no corpo inteiro do participante, afetando-o, integrando-o inteiramente à descoberta de si e do seu entorno, trabalhando a percepção, que consiste no processo de dotar de significado uma determinada experiência. A Percepção então passa a ser o ato de interpretar os estímulos que nos foram agregados através dos órgãos sensoriais, como propõe Jorge Larrosa Bondía, "a saber, pensar a educação a partir do par experiência/sentido", um par que impele e envolve o corpo. (BONDIA, 2002:19).

Na próxima proposta prática, envolvendo agora a relação com o outro, os participantes, ainda sem utilizarem a visão, foram dispostos em duplas, um de frente para o outro. As duplas deveriam estabelecer unicamente o contato físico das mãos do seu par, com o mesmo objetivo do exercício anterior, assimilar o máximo de informações sobre essa parte do corpo do seu colega, percebendo suas características físicas singulares. Após alguns minutos de investigação, ainda sem abrirem os olhos, eles foram andando lentamente pelo espaço, se misturando com os outros colegas. Depois de estarem bem misturados, tiveram que, como cabras cegas, procurar seu par, suas mãos parceiras. Esse jogo aproximou e descontraiu muito o grupo, pois esse é um dos valores do jogar.

Numa tentativa de resumir as características formais do jogo, poderíamos considerá-lo uma atividade livre, conscientemente tomada como "não-séria" e exterior à vida habitual, mas ao mesmo tempo capaz de absorver o jogador de maneira intensa e total. É uma atividade desligada de todo e qualquer interesse material, com a qual não se pode obter qualquer lucro, praticada dentro de limites espaciais e temporais próprios, segundo uma certa ordem e certas regras (HUIZINGA, 2014: 84).

Após se "descontraírem" e encontrarem seus pares, agora com os olhos abertos, formamos uma grande roda para uma apresentação de cada um. O corpo possui um nome e esse nome será dito. Após todos se apresentarem, repetimos a apresentação junto com uma ação do corpo. O participante fala o seu nome e realiza agora um movimento do corpo que o represente. Em seguida, repetimos com o nome de um colega. Depois de variações da proposta, adicionando movimentos, deslocamentos e gestos, os participantes passaram a conhecer todos os que estavam presentes e realizando e exercitando o seu potencial criador com o corpo em relação com o outro na forma de um jogo. Na concepção do pensador alemão Johan Huizinga, em Homo Ludens, o jogo tem uma função "significante" na vida, isto é, encerra um determinado 
sentido. No jogo existe alguma coisa "em jogo" que transcende as necessidades imediatas da vida e confere um sentido à ação. Todo jogo significa alguma coisa. "Seja qual for a maneira como o considerem, o simples fato do jogo encerrar um sentido implica a presença de um elemento não material em sua própria essência" (HUIZINGA, 2014: 84).

A próxima dinâmica aplicada relacionou o corpo, o espaço e os outros participantes, todos caminhando no espaço, variando as direções, sem tocar em ninguém e em nada, percebendo que apenas um participante por vez poderia estar parado sem nenhum movimento aparente no espaço. Todos, tanto os que estão andando, como o participante parado, criam uma unidade de corpos e mentes. Para Pavis (2017:22), direcionando a trindade filosófica de Deleuze, baseado em conceito, percepto e afeto, "as dimensões do percepto e do afeto estão intimamente ligadas”. E comprova a ligação citando Deleuze: “O ser da sensação, o bloco do percepto e do afeto, aparecerá como a unidade ou a reversibilidade do senciente e do sentido, seu íntimo entrelaçamento, à maneira de mãos que se estreitam”. Essa unidade criada pelo corpo/mente busca um ser consciente, inteiro e pronto para realizar a experiência de si e de relacionar-se com o outro, se desenvolvendo criativamente, expressivamente, sensorialmente, e, principalmente humanamente.

Prosseguindo com a oficina, partimos agora para o jogo de interação com o outro: uma improvisação realizada em duplas, denominada espelho, um dos mais tradicionais nas artes da cena. Nesse jogo, a dupla deve fixar o olhar nos olhos do outro e permanecer se olhando durante toda a atividade. Assim, um dos participantes cria movimentos com todo o corpo, bem lentamente e a movimentação deverá ser reproduzida pelo par, ao mesmo tempo. Os movimentos iniciaram sem deslocamentos, depois com deslocamentos e depois o "comando" foi trocado. 


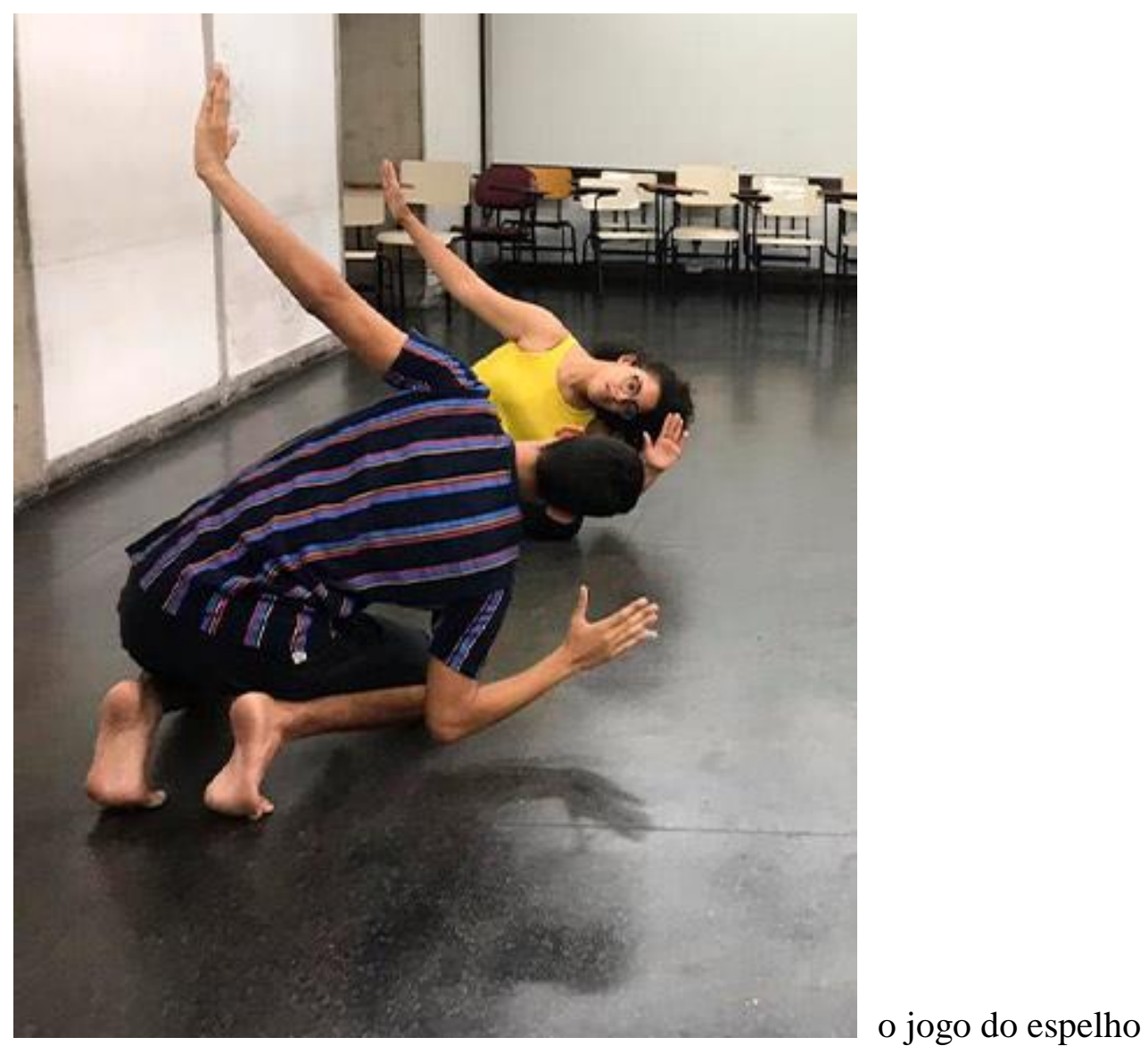

Acompanhando o desenvolvimento do exercício de espelho, é possível notar um grande envolvimento por parte dos participantes com esse tipo de jogo, uma forma de afeto por despertar o potencial criador, ao mesmo tempo uma visão perspectivada do corpo do outro e de si, através do outro.

Segundo a artista plástica Fayga Ostrower (1995), o potencial criador não é outra coisa senão esta disponibilidade interior, esta plena entrega de si e a presença total naquilo que se faz. $\mathrm{Ou}$, segundo Ryngaert, presença enquanto forma de "energia irradiante cujos efeitos sentimos antes mesmo que o ator tenha agido ou tomado a palavra, no vigor de seu estar ali” (apud Pavis, 1999: 305). Essa presença, esse vigor do estar ali, compõe um corpo especial na relação com o espaço, como afirma Gil: "Este corpo compõe-se de uma matéria especial que tem a propriedade de ser no espaço e de devir espaço, quer dizer, de se combinar tão estreitamente com o espaço exterior que daí lhe advém texturas variadas: o corpo pode tornar-se um espaço interior-exterior produzindo então múltiplas formas de espaço...” (GIL, 2004: 56). 


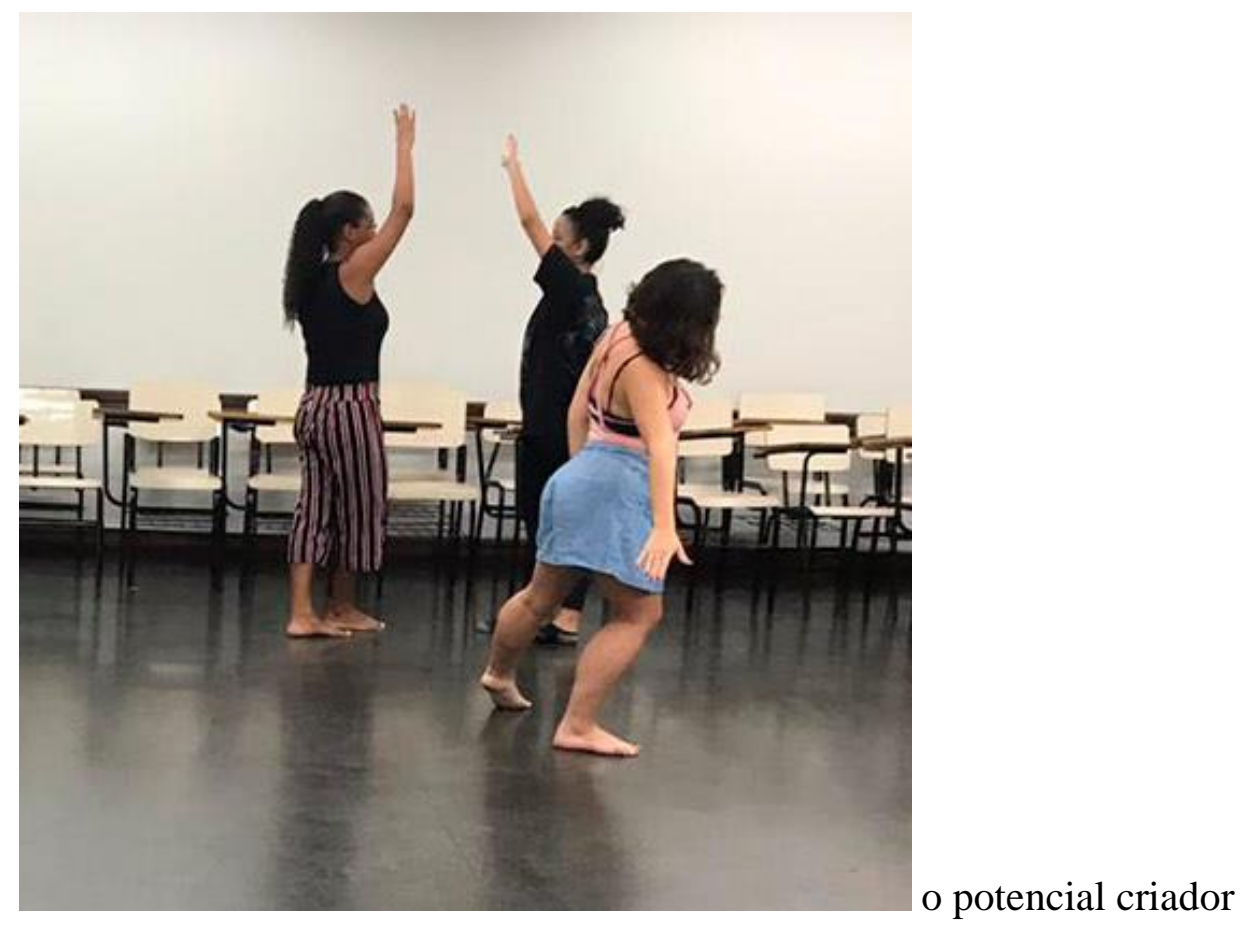

Para finalizar o encontro, realizamos um relaxamento em pequenos grupos, de cinco a seis participantes, em roda, abraçados e de olhos fechados, objetivando o movimento do conjunto, como o movimento de rosquear, para um lado e para o outro lado. Esse exercício tem como objetivo buscar uma unidade no grupo.

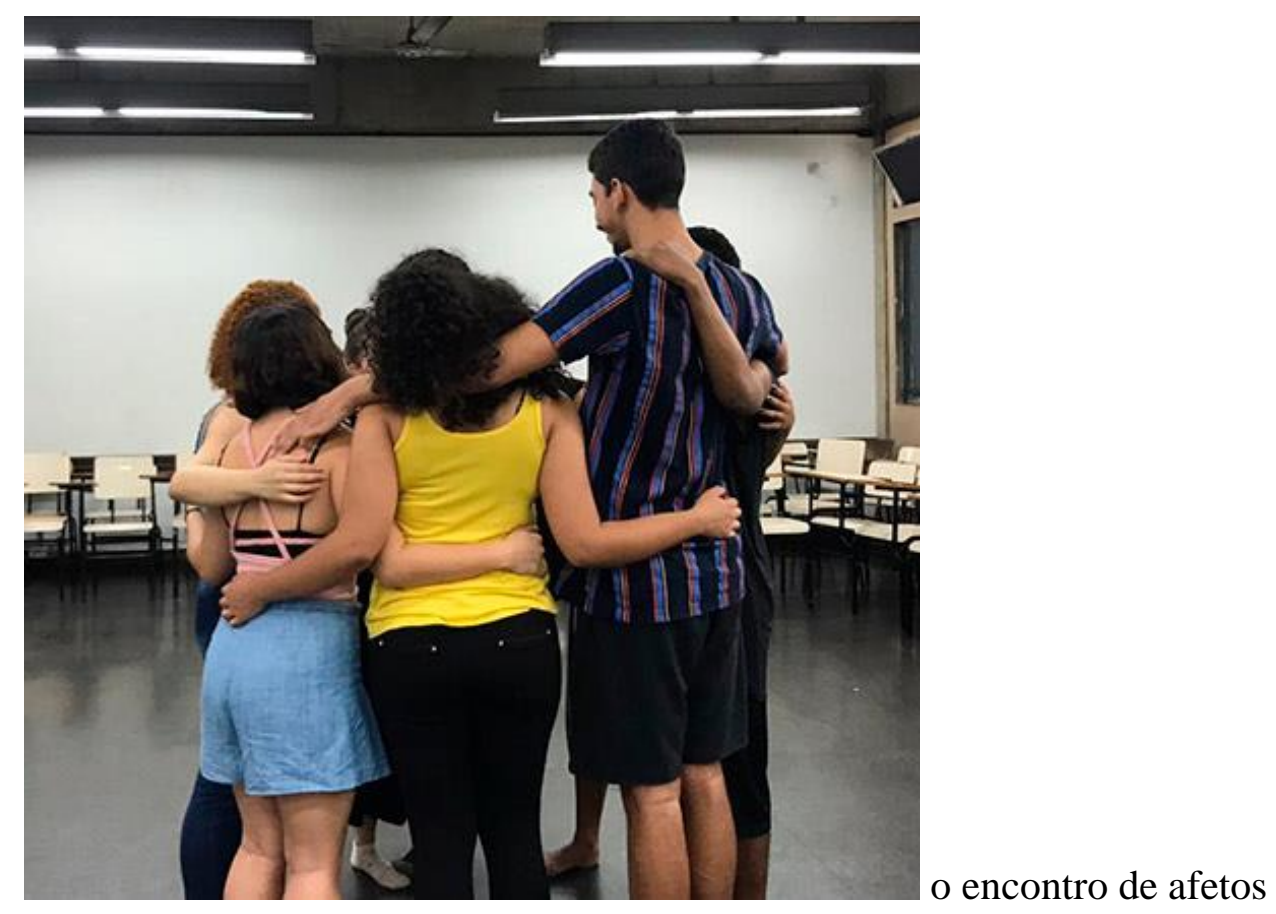




\section{Conclusão}

Foram expostas aqui algumas propostas de exercícios realizadas na oficina denominada A Poética do corpo e sua inteligência pelo percepto e pelo afeto. Iniciamos os trabalhos partindo de conceitos de corpo, consciência, afeto, jogo e experiência. Compartilhamos vivências ao relacionar esses conceitos com a poética do corpo, do movimento, dos afetos, criando um encontro singular, encantador, que envolve vários territórios físicos e de ideias e enaltece a consciência de si e do outro, criando assim uma rede de subjetividades e, especialmente de afetos, pois, como afirma Pavis (2017), o afeto é uma relação entre o corpo e mundo.

Nesse sentido, a prática artística absorvida pelo corpo é um excelente caminho para o desenvolvimento dessa inteligência e sensibilidade de si e do outro, por promover o encontro de subjetividades, explorando a percepção e os sentidos do corpo, ampliando a conscientização, estimulando os afetos, como aquilo que move e tem a capacidade de mexer. Para Pavis (2017), os afetos alimentam a energia pulsional dos participantes, que, muitas vezes, não alimentam essa pulsão por serem engolidos pelo excesso de informação ou até pela falta de tempo; com isso, quase não encontram “espaço” em suas vidas para essa prática de si, para a prática sensível. Como consequência da falta de tempo e de espaço, muitas vezes o indivíduo se distancia de si, dos movimentos do afeto da vida, como uma bolha que o torna incapaz, como afirma Jorge Larrosa Bondía: "É incapaz de experiência aquele a quem nada lhe passa, a quem nada lhe acontece, a quem nada the sucede, a quem nada o toca, nada lhe chega". (BONDIA, 2002: 21)

$\mathrm{O}$ corpo fornece e recebe sensações que permitem uma afetiva objetividade em ação, que, por sua vez, estabelece uma linguagem constituída por pensamentos, sentimentos, movimentos e emoções de natureza universal, fundamentais ao desenvolvimento humano. Daí a importância de eventos dessa natureza, que estimulam e exploraram o aspecto da integração consigo e com o outro e, principalmente, com o mundo, através da ludicidade de uma poética corporal.

Podemos afirmar que, na poética do encontro, os corpos provocam e percebem sensações que permitem uma tradução afetiva. O afeto é subjetivo. Ele é o resultado de como o corpo reage às transformações em ação. O corpo fornece as sensações que permitem uma afetiva objetividade em ação, que, por sua vez, estabelece uma linguagem que se expressa como a consciência de si, constituída por pensamentos, sentimentos e emoções de natureza universal e poética. 


\section{Referências}

ARTAUD, Antonin. O teatro e seu duplo. Tradução de Teixeira Coelho. São Paulo: Martins Fontes. 1993.

BONDIA, Jorge Larrosa. Notas sobre a experiência e o saber de experiência. Rev. Bras. Educ. [online]. 2002, n.19, pp.20-28. ISSN 1413-2478. https://doi.org/10.1590/S141324782002000100003

GIL, José. Movimento Total. O corpo e a dança. São Paulo: Iluminuras, 2004.

MEYER, Sandra, O corpo do ator em ação. In: GREINER, Christine; Amorim, Claudia (Orgs). Leituras do corpo. Segunda edição-São Paulo: Annablume, 2010. p.107-121

HUIZINGA, Johan. Homo ludens: o jogo como elemento da cultura. São Paulo: Perspectiva. 2014

OSTROWER, Fayga. Acasos e criação artística. Rio de Janeiro: Campus, 1995.

PAVIS, Patrice. Dicionário da performance e do teatro contemporâneo. São Paulo: Perspectiva, 2017.

SIMHA, André. A Consciência: Do corpo ao Sujeito. Rio de Janeiro: Vozes, 2009.

Maria Lúcia Galvão Souza

Universidade do Estado do Rio de Janeiro

E-mail: $\underline{\text { mlgalvao@uol.com.br }}$ 